\title{
Accelerating Experience with Live Simulation of Designing Complex Systems
}

\section{Prof. William Robinson, Stevens Institute of Technology}

Bill Robinson is the Program Director for Systems Engineering and Distinguished Service Professor at Stevens Institute of Technology. He has delivered more than 60 graduate Systems Engineering classes at Stevens in many different formats, including standard semester-based classes, synchronous multi-location distance learning, online distance learning, and on-site modular formats. Prior to coming to Stevens Bill worked for more than twenty-five years in different technical and business leadership roles. For many years, he was Vice President for Bell Labs. Other positions he held include Vice President and General Manager for EasyLink Services Corporation as well as President of Innovation and Quality Solutions. Bill has received numerous quality, reliability and innovation leadership awards and has authored several technical and process quality papers. He was twice awarded the Bell Labs President's Award for innovation and Technical Excellence. Bill received a BSEE from the University of Connecticut and a MSEE from Rensselaer Polytechnic Institute. He is a senior member of the American Society for Quality, member of INCOSE and a Six Sigma Master Black Belt.

\section{Dr. Michael Pennotti, Stevens Institute of Technology}

Michael Pennotti, Ph.D. is Director, Systems Programs and a Distinguished Service Professor in the School of Systems and Enterprises at Stevens Institute of Technology. Prior to joining Stevens in 2001, Mike spent twenty years in systems engineering practice and leadership at Bell Laboratories, primarily working on undersea surveillance systems for the Navy. He then spent ten years applying the same principles and practices to organizations and enterprises as a member of the senior leadership teams of three different AT\&T businesses. Since joining Stevens in 2001, Mike has helped develop the SDOE Program into one of premier systems engineering graduate programs in the U.S. He has taught Fundamentals of Systems Engineering and System Architecture and Design to more than 1000 industry and government students and has delivered workshops in Systems Engineering and Architecting, Systems Thinking, Critical Thinking, and Technical Leadership across the U.S. and in Europe. He is a Fellow of the International Council on Systems Engineering and a senior member of both the IEEE and the American Society for Quality. He holds Ph.D. and MS degrees in Electrical Engineering from the Polytechnic Institute of New York, a BEE from Manhattan College, and is a graduate of the AEA/Stanford Executive Institute for Technology Executives. 


\title{
Accelerating Experience with Live Simulation of Designing Complex Systems
}

\author{
Introduction
}

Experience is generally thought to be something engineers acquire on the job, a product of lessons learned from real-life successes and failures. With the demand for skilled engineers exceeding supply ${ }^{1,2}$, however, there is great interest in whether and how this process might be accelerated. This is of particular concern as the engineering workforce becomes increasingly global, with distributed teams having to collaborate at a distance, without the benefit of frequent face-to-face meetings to stimulate creativity and resolve ambiguities ${ }^{3}$. Recent experiments have demonstrated the potential for accelerating experience by using live simulations of realistic, complex, system design projects. Engineers at different levels of experience, who have been immersed in these simulations, have demonstrated insights usually associated with time on the job. This raises the possibility that useful experience might be acquired at dramatically reduced time, cost and risk.

We have designed and conducted multiple simulations to expose students to the complexity, confusion, and decision-making and leadership challenges encountered in complex system design and development projects. These interrelated simulations have included: Design Simulations, Leadership Simulations, Customer Simulations, and Peer Review Simulations.

The simulations allowed students to discover that they had been unknowingly locked within several mental 'boxes'. They observed that the decisions they made during the simulations were unpredictable and unrepeatable; that they had consistently failed to reframe the problem when confronted with obstacles and failures; and that, when faced with the same problem, different teams produced different solutions. As a result, although the solution produced by each team met all the documented requirements, they all tended to be over-designed, under-tested and ultimately failed to work. Despite warnings by mentors and management, it took this firsthand experience for the lessons to really sink in.

Integrated Live Simulations of Designing Complex Systems

The first simulation, the Design Simulation, involved twenty-eight early-career engineers who had been selected for the Leadership Development Program of a large, international technologybased company. The students were enrolled in Stevens' Systems Engineering Graduate program and were located in five geographically dispersed locations. This initial simulation provided the baseline system design used in all of the subsequent simulations.

The Design Simulation was initiated by defining specific roles. Class instructors acted as the "Customer" for the system being designed, developing the requirements and Statement of Work (SOW) for the system and making all the key program-level decisions, e.g., competition win/loss, throughout the simulation.

The students' functional leaders and mentors acted as the “Technical Evaluation Team,” providing feedback and coaching for the design teams throughout the simulation, and evaluating the results at the end. 
The students themselves were organized into two competing "Design Teams". Both teams were asked to independently design, document, and implement a complex, autonomous command and control system that would provide route-finding capabilities to assist a vehicle safely navigate a hostile urban environment. The design tasks included system architecture development, hardware and software design, system integration and test and proof of concept demonstration. The teams were deliberately constituted so as to maximize the geographic distribution of the teammates in order to simulate the reality of the global engineering environment. The competition between the two design teams and the geographically distributed design environment were integral to the design of the simulation.

The system the students were asked to design consisted of a suite of small autonomous unmanned vehicles called Seekers. Seekers travel in conjunction with a High-Value Asset (HVA) (such as a supply truck or ambulance). The mission of the Seekers is to assist the HVA by identifying and locating road hazards or obstacles. Sensors on the Seekers transmit data back to a Portable Central Processor (PCP) carried on-board the HVA to provide safe routing directions from an initial position to a final destination.

Two phases of system development were defined by the Customer: the Command and Control Proof of Concept (POC) phase and the Full Scale Prototype (FSP) phase. The POC was intended to demonstrate and validate the capability of each design to perform the required routing control. The Customer assumed the design teams would select a small/inexpensive commercial-off-theshelf robot for their POC solution (e.g., Lego's Mindstorms), although this was not a requirement. The goal of the POC competition was to control the HVA to travel from start to end through a maze as quickly as possible with the winner moving on into the FSP phase. While the FSP phase was never really intended to take place, it was simply established as the ultimate goal for the teams.

Both design teams worked very hard and met every program milestone over the first several months of the simulation, including several design reviews with the Technical Evaluation Team. Despite this effort, it quickly became apparent that both design teams were heading down a path toward highly custom and very complex POC designs. While the Technical Evaluation Team pointed out this risk, both design teams continued to struggle with the individual desires to make their designs exceptional, as well as with issues caused by the remote team locations.

A couple of weeks before the scheduled POC competition, each team separately informed the Customer by e-mail that they were encountering "significant problems" during the final test and integration of their POC designs. Both teams requested significant schedule relief and additional funding. Instead, the Customer announced that the original Competition schedule would hold, but that the competition rules would be revised to require only six simple tests. When the Competition did take place, as scheduled, one team's design passed only three of the six revised/simple tests and the other team's design was able to pass only two of them. 
Feedback and Lessons Learned were solicited in several ways after the simulation, including collectively from each team, as well by each student individually. Three clear themes emerged from that feedback:

- Both POC designs were over-engineered, e.g., custom designs and multiple operating systems, and therefore too complex for the intended purpose.

- Both teams underestimated the test and integration effort required for their POC designs and neither allowed enough time to accomplish these late-stage, critical activities.

- Both teams underestimated how important it was to plan and manage activities and communications across a geographically distributed team.

The design teams concluded that these three themes were the primary root causes of why neither design was able to pass the (simplified) completion tests.

The Leadership Simulation involved twelve mid-career technical leaders from several companies and organizations who were participants in Stevens’ Technical Leadership Master’s Degree Program. The students were organized into three competing teams that played the role of the “Technical Leadership Team” of a fictitious company, one that was competing to win a large development contract.

Once again, the class instructors acted as the "Customer" for the system being designed. A fictitious “Technical Fellows Team” was added to this simulation to provide 'feedback' to the students, and the system "Design Teams" were the design teams of the original simulation described above.

Using artifacts generated in the Design Simulation, the three Technical Leadership Teams were led back through the original POC design process as though the program were unfolding in real time. The leadership teams were asked to assess the designs at each step, providing feedback as if they were technical leaders doing so in real time.

At the end of this eight month simulation, the Technical Leadership class was asked, "What happened with the original designs? Why did they both fail?" They said that while both designs were clearly over-engineered, no one seemed to push back when it seemed obvious they were heading for a cliff. "We do this all the time!”, added one the students. They also observed that the simulations helped point out to the students that leadership and communication across geographically diverse teams is difficult and needs to be experienced to learn how to deal with it. In the words of one of the Technical Leadership students, "Left on their own, fish will swim together ... but not necessarily in the right direction... they need a Shark!”.

The third integrated simulation, the Customer Simulation, involved forty-nine mid-career government acquisition professionals organized into nine competing teams for the simulation. The teams each played the role of the "Team Leads" for a fictitious “Technical Evaluation 
Team” for a major new government acquisition program. In other words, if this design had been a real program, they would have represented the actual customer!

Once again, the class instructors acted as the "Customer" for the new acquisition and the "Design Teams” were the original design teams of the original simulation described above.

The nine customer teams were led back through the original POC designs as if the program was unfolding in real time and were asked to assess the designs at each step and to provide feedback as if they represented the actual customer.

At the end of this one-week simulation, this class was also asked, "What happened with the original designs? Why did they both fail?” Most of their feedback was quite consistent with that of the students in the previous simulation, but some had surprising insights from the perspective of a customer:

- The design teams should have helped the customer think about what they really needed (push back if it would help the program).

- Many of the POC requirements were not needed and were obstacles for success.

- The design teams should have thought of alternate solutions to the "obvious" one.

- Make sure the solution is not over-designed.

The final simulation, the Peer Review Simulation, closed the loop back to the initial Design Simulation. The Peer Review Simulation involved seventy-three early-career engineers from a subsequent cohort of the same Leadership Development Program as the original design group. They were organized into nineteen competing teams and asked to play the role of Peer Review Teams for the simulation. The other simulation roles were similar to the previous simulations, with the two system designs once again being the original designs from the first simulation. In other words, these students were asked to review and assess the designs produced by their peers.

At the end of this one-week simulation, the class was also asked "what happened?" Interestingly, they mimicked the feedback and lessons-learned from their peers, the original design teams/class that proceeded them:

- The designs were over-engineered.

- The teams underestimated the time and difficulty of system testing and integration.

- The teams underestimated how important it was to plan and manage activities and communications across a geographically diverse team.

Inside the Box(es)

Having observed that the simulations allowed participants at every level to develop insights usually associated with on-the-job experience, and having verified that both practitioners and leaders viewed the simulations and the results they produced as realistic, the question then arose 
as to whether we might learn something about real life experience from observing the behavior of participants in the simulations. In particular, would the controlled environment of the simulations allow us to see things that are difficult to observe in the more chaotic experience of real life? We concluded that the answer was a resounding yes.

We began with the Design Simulation. How could it have be that teams of the "best and the brightest” engineers, from the finest universities in the country, had failed to successfully complete a task that many high school, and even middle school, students accomplish in competitions every year. One does not have to search the Internet for very long to find ample evidence that the task they were assigned was well within their technical capabilities. In pondering this enigma, it became clear that the outstanding capabilities of the students contributed to the problem. We saw the students as locked in a metaphorical box we came to call the "Technical Box."

What the simulation had done was to take young, highly talented engineers, immerse them in two intensive technical courses, and then give them a technically interesting design problem to solve. Further, they had been formed them into separate design teams and challenged to participate in a final competition. In hindsight, it was not surprising that they produced overly complicated designs, and that they then spent so much time trying to perfect them that there was not enough left for integrating, testing and troubleshooting their designs.

The problems encountered by the engineers were compounded by what we came to call the "Programmatic Box." Because the simulation included the development of a formal, competitive proposal, the students were required to perform a large number of what seemed to them to be unrelated tasks. For example, they had to design a full scale prototype in addition to a proof of concept demonstration, to produce management and cost volumes, in addition to a technical volume, to organize themselves into Integrated Product Teams and choose team leads. Furthermore, they had to manage themselves over dispersed geographic locations with insufficient travel funds to allow them to meet in person until the final demonstration, simulating the development challenge often encountered by today's global engineering workforce. These programmatic activities often served to distract the students from the technical task at hand and delay the identification and solution of problems.

The Leadership Simulation introduced a new set of concerns; ones that especially impacted the technical leaders who were asked to oversee the design teams. The leaders had been told that the competition was a "must win" project for their business, and the pressure that created appeared to inhibit them from reframing the problem when the design teams got into trouble. Instead, they responded to each successive difficulty by making the best of a bad situation. In the end, the leaders realized that they had missed numerous opportunities to press reset, redefine the problem, and move off in a new direction. We called this the "Leadership Box." 
Finally, the Customer Simulation revealed the problem had one more dimension, one that was identified by the acquisition professionals themselves. Upon reflecting on their experience after the simulation was complete, they were at first concerned that the design teams had not deviated from the customer-specified requirements, even when it had become clear that better solutions existed than those called for in the solicitation. As the discussion progressed, however, they recognized that, under the terms of a competitive procurement, with a formal Request for Proposal, predetermined evaluation criteria and the ever present threat of protests, there would have been no way for them to have given a respondent credit for such deviations even if they had proposed them. In effect, the procurement process itself constrained the solution to be developed within pre-established norms. We called this the "Procurement Box."

So in the end, we concluded that the answer to the question of how talented engineers had failed to achieve their assigned task could be summed up in the form of a nested set of four metaphorical boxes: a Technical Box that captured the imagination of the engineers and encouraged them to overdesign the solution; a Programmatic Box that distracted them from their technical task; a Leadership Box that inhibited those assigned to oversee their efforts from reframing the problem when planned activities were unsuccessful; and a Procurement Box that constrained participants at every level to focus exclusively on the problem that problem as it had been specified rather than on developing what the customer really needed.

Avenues for Further Research

Our plans for further research in this method for Accelerating Experience for the global engineer includes redesigning the simulations for various system applications and exploring the impact of utilizing massively multiplayer online game (MMOG) and crowdsourcing methods to engage broader interaction into the simulations. In addition, we plan to use these extended simulations to provide an avenue to perform controlled experiments to expand the insight of how experience is gained and how it is used by the global engineer.

Bibliographic Information

1. National Defense Industrial Association, "Top Systems Engineering Issues In the U .S. D efense Industry," NDIA Systems Engineering Division Task Group Report, September 2010.

2. Goncalves, D. "Developing systems engineers.” Proceedings Portland International Conference on Management of Engineering \& Technology (PICMET) 2008, Capetown, South Africa, July 27-31, 2008.

3. Final Report of the Global Engineering Excellence Initiative: Educating the Next Generation of Engineers for the Global Workplace, Published by Continental AG, Hanover, Germany, 2006, ISBN 3-9811322-1-1. 